\title{
NOTAS SOBRE 0 GOVERNO DE COISAS E CORPOS NA ENCANTARIA MARANHENSE
}

\section{NOTES ON THE GOVERNANCE OF THINGS AND BODIES IN THE ENCHANTMENT IN MARANHÃO}

\author{
Martina Ahlert*
}

\section{Introdução}

Há alguns anos me dedico a uma pesquisa etnográfica no interior do Maranhão sobre como as pessoas levam suas vidas na companhia não apenas de outras pessoas, mas de seres conhecidos como encantados. Os encantados se fazem presentes em momentos rituais, quando são invocados em pontos cantados e acompanhados por tambores e cabaças, em espaços chamados de tendas, terreiros ou salões das religiões afro-brasileiras encontradas no estado. Poderiam assim ser descritos a partir de certa liturgia religiosa, de observações sobre in- dumentária e preceitos, ou mesmo de sua mitologia expressa nos pontos e no seu contar sobre si mesmos.

Entretanto, os encantados também se fazem presentes em outros momentos. No que poderíamos considerar as atividades cotidianas das pessoas - cozinhar, beber cerveja em um bar, lavar a casa, cuidar dos filhos ou trabalhar na roça, os encantados aparecem, enviam sinais, trazem recados. Além disso, ou para além de sua presença nos corpos por intermédio da incorporação (ou possessão), eles possuem objetos espalhados pelas casas, estampam fotografias presas às paredes, são considerados “donos"

\footnotetext{
* Doutora em Antropologia Social pela Universidade de Brasília. Professora do Departamento de Sociologia e Antropologia (DESOC) e do Programa de Pós-Graduação em Ciências Sociais (PPGCSoc) da Universidade Federal do Maranhão - UFMA (São Luís/MA/BR). E-mail: ahlertmartina@gmail.com.

1. Uma primeira proposta desse texto foi apresentada no Seminário "Moçambique, Caribe e Alhures: composições materiais e imateriais", realizado no Museu Nacional em 30 de novembro e 01 de dezembro de 2017. Neste contexto, agradeço à Olívia Maria Gomes da Cunha, Alline Dias Torres da Cruz e aos colegas do Laboratório de Antropologia e História (LAH) e do Núcleo de Antropologia Simétrica (NANSI), do Programa de Pós-Graduação do Museu Nacional, da Universidade Federal do Rio de Janeiro. Agradeço ainda aos pareceristas da REPOCS pelo retorno atencioso e instigante.
} 
de determinados espaços e, especialmente, são personagens e protagonistas de conversas dificilmente consideradas religiosas, no sentido estrito do termo.

Desde que comecei a pesquisar os encantados no Maranhão, foram essas situações que chamaram minha atenção, pois elas evidenciavam o caráter ordinário ou costumeiro das experiências de pessoas e encantados. Evidentemente, essa aposta teórico-metodológica não é nova (BORGES, 2007; NDEBELE, 1986) e reforça um aspecto enfatizado em alguns estudos sobre religião: a incapacidade de recortar/moldar ou modular a experiência religiosa como uma esfera autocontida e claramente delineada em relação àquilo que compõe a vida das pessoas como um todo (GIUMBELLI, 2008). É a partir dessas experiências que marcam o cotidiano, que analiso a forma como seres intangíveis conhecidos como encantados, se fazem presentes e afetam a vida de pessoas, mulheres e homens no interior do estado maranhense. Esse contexto de pesquisa não passa incólume à problemática central deste artigo.

Desde que iniciei a pesquisa de campo, em 2010, me instigou certa afırmação recorrente para explicar o engajamento de pessoas com as religiões afro-brasileiras, que remetia a aspectos relativos à pobreza e à política. 0 estado do Maranhão tem destaque negativo seja quanto a índices e indicadores utilizados para mensurar o desenvolvimento humano, que perpassam renda, escolaridade e acesso a diversos serviços públicos ${ }^{2}$, ou quanto a domínio político de determinada família que concentrou, durante anos, importantes cargos do Executivo $^{3}$. Apesar da complexidade de cruzamentos que configuram os marcadores sobre as condições de vida no Maranhão, é comum culpabilizar as pessoas pelas condições nas quais vivem a partir da identificação de ausências (de estudo, esclarecimento ou conscientização política). Na explicação em tela, a religião é acionada em conjunto com tais considerações, na medida em que se concebe o engajamento religioso como fruto (e causa da pobreza), e como instrumento obliterador das relações políticas.

Com a intenção de problematizar essa explicação, eu gostaria de trabalhar neste texto uma categoria que surgiu durante a pesquisa de campo, utilizada para falar da relação entre pessoas e encantados: a ideia de "governo". Um encantado recebido por $\mathrm{Rita}^{4}$, uma filha de santo de uma religião chamada Terecô, certa vez mandou um recado para outra entidade dizendo "você já governou essa menina por muito tempo". Dona Luizinha, mãe de santo da cidade de

2. O Maranhão é um estado conhecido pelas altas taxas de analfabetismo e por diversos problemas relacionados à ausência de serviços públicos. Em 2017 ocupava o 24ํo lugar no ranking do Índice de Desenvolvimento Humano (IDH) entre os 27 estados brasileiros.

3. José Sarney se elegeu governador do Maranhão em 1966, depois de ser deputado estadual e federal. Tornou-se ainda presidente do Brasil (em 1985) e atualmente é senador pelo Amapá. Seus aliados e sucessores governaram o estado maranhense até as eleições de 2014, quando Flávio Dino, do Partido Comunista do Brasil, foi eleito governador.

4. A maioria dos nomes das pessoas citadas no texto não foi alterada, na medida em que, em campo, f1cou evidente para mim que gostariam de ter seus nomes relacionados às contribuições dadas à pesquisa. Na história de Rita e Benta, entretanto, por se tratar de uma situação que considero delicada, optei pelo uso de nomes fictícios. 
Codó, interior do Maranhão, disse, sobre a força dos encantados, que "tem que viver pra eles. [A pessoa] não se governa. Ela é governada”. Seu Libâneo, uma liderança da comunidade quilombola de Santa Rosa dos Pretos, em Itapecuru-Mirim, também município maranhense, afirmou, quando falava das capacidades dos espíritos e invisíveis que "nesse mundo ninguém se governa".

Tomarei a categoria "governo" a partir de duas situações específıcas: a primeira discorre sobre objetos e corpos, e remete à história de vida de Dona Benta, uma mulher que vivia na cidade de Codó e não queria ter encantados; a segunda foi contada por Seu Libâneo, no povoado de Santa Rosa dos Pretos, em Itapecuru-Mirim, e trata da relação dos encantados com a natureza, especificamente com determinados espaços impactados por projetos de desenvolvimento. Minha intenção é tomar esse governo para provocar certa ideia de autonomia e esclarecimento que nega a presença dos encantados e suas diversas agências no mundo e que, desta forma, desqualifica um amplo conjunto de ações, experiências e pessoas.

\section{Encantados e governo dos encantados}

Existem, segundo parte da literatura sobre a encantaria maranhense (FERRETTI, 2000; 2001; BARROS, 2000), três religiões afro-brasileiras no Maranhão: a Pajelança, localizada na região da Baixada, onde são recebidos encantados da linha de água doce; o Terecô, encontrado na região dos Cocais, onde existe a presença de encantados da linha da mata; e o Tambor de Mina, loca- lizado especialmente na capital e seu entorno, onde são recebidos encantados da linha de água salgada. Apesar dessas definições, na experiência de vida dos sujeitos com os quais convivi em campo - chamados aqui genericamente de "brincantes" , tais perspectivas são fluidas, e entidades que pertenceriam a religiões diferentes circulam em contextos e terreiros diversos. Poderíamos dizer, nesse sentido, que os encantados e sua mobilidade desafiam nossos desejos classificatórios, propondo conexões e não substancializações (NYAMNJOH, 2015).

Encantados são, portanto, seres "recebidos” em diferentes religiões afro-brasileiras encontradas no Maranhão, que estão organizados em famílias, possuem nomes próprios e saberes que os diferenciam. Compreende-se que essas entidades foram pessoas, que desapareceram sem passar pela experiência de morte, quando foram viver na encantaria - uma espécie de outro mundo, entre mundo ou diferente dimensão da experiência (FERRETTI, 2000; AHLERT, 2013). Da encantaria, elas vêm para dar conselhos, trabalhar, ajudar, castigar, curar e dançar tambor. Uma pessoa que possui "mediunidade" (ou seja, capacidade de "receber" encantado) tem a responsabilidade de incorporá-las ou com elas se relacionar de formas diversas, como por intermédio do contato em sonhos, o dom da vidência ou ainda certa sensibilidade para compreender sinais e avisos ${ }^{5}$. Embora o termo "possessão" seja bastante recorrente na literatura sobre religiões afro-brasileiras ou de matriz africana no Brasil e no exterior, ele é ausente nos contextos de pesquisa

5. Em outro momento (AHLERT, 2016), busquei pensar as diferentes relações entre pessoas e encantados nos diversos estágios da vida de um terecozeiro, pensando na aproximação e nas estratégias de afastamento entre eles. 
aqui trabalhados, onde se emprega termos como "receber encantado", "carregar encantado" ou "estar com encantado".

Paul Johnson (2014) pontua o caráter inerentemente político da discussão sobre possessão, pois a partir dela o corpo negro, ocupado pelos espíritos, historicamente desafıa noções de indivíduo, propriedade e contrato tal como estabelecidas por determinada filosofia política ocidental. A possessão, lida pelo olhar colonizador, era utilizada para legitimar regimes de desumanização e escravidão.

Ideias rodopiantes sobre pessoas enquanto propriedade, e corpos sem vontade, foram a matriz da qual a possessão e suas múltiplas valências emergiram, já entrelaçadas. A possessão de espíritos era um híbrido por meio do qual a Europa interpolou, e foi em seguida infiltrada por múltiplos Outros fantasmagóricos. Ela conectou noções de pessoa, religião e da boa sociedade (JOHNSON, 2014, p. 93).

Achille Mbembe (2015) sugere uma relação entre o tráfico de escravos, o colonialismo e questões da teoria social ocidental que levaram à compreensão do continente africano como lugar de incompletude e caos, e de negação da contemporaneidade. Nesse contexto, a ideia de uma pessoa diferenciada do sujeito visto como autônomo e capaz de se autolegislar (o indivíduo moderno) encontrou ressonância ${ }^{6}$, ainda que, como demonstra Palmié (2006), a não distinção entre pessoas e coisas (e a não coincidência entre pessoa e corpo) também fosse uma questão presente no Ocidente.

James Leach (2007) problematiza a relação entre determinada concepção de indivíduo, a ideia de propriedade e a necessidade do controle das paixões (vistas como contrárias à racionalidade). Para o autor, esses elementos presentes na filosofia política ocidental fundamentaram uma concepção de natureza humana e justificaram a regulação do Estado ${ }^{7}$. A ideia de propriedade “... parece exercer uma forte influência sobre a imaginação em todo lugar. É quase inevitável visões prontas (imediatas) de limites, exclusividade e controle" (LEACH, 2007, p. 100 , tradução nossa) ${ }^{8}$. No contexto da colonização, portanto, a possessão era vista como a impossibilidade da propriedade do próprio corpo, como índice de descontrole e como elemento legitimador da escravidão.

Em vez de lamentar a ausência da noção de indivíduo moderno em determinados

6. 0 autor critica a seguinte perspectiva: "Enfım, a pessoa, nessas sociedades, teria predominância sobre o indivíduo, essa derradeira categoria sendo, acrescentemos, “uma criação propriamente ocidental”. Em lugar do indivíduo, teríamos essas entidades cativas dos signos mágicos, no seio de um universo encantado e feérico onde o poder de invocação e de evocação substituiriam o poder de produção, e onde o maravilhoso, a fantasia e o capricho coabitariam não somente com a possibilidade da desgraça, mas com sua realidade" (MBEMBE, 2015, p. 372).

7. Sobre pessoa e propriedade, afirma James Leach: "Isso talvez possa ser melhor feito ao se estabelecer a particularidade da forma da pessoa envolvida. Nessa forma, a pessoa é concebida como um ser internamente especificado, dotado de direitos naturais, e capaz, como indivíduo, de trabalhar e criar elementos no mundo externo a fim de facilitar sua sobrevivência, seu próprio desenvolvimento e o desenvolvimento de um sistema de instituições que coletivamente fazem a 'civilização' (...) 0 sujeito é definido como aquele que possui atributos e que controla objetos” (LEACH, 2007, p. 109-110, tradução nossa).

8. No original: “... seems to exercise a strong hold over imaginations everywhere. It's almost inevitable prompts visions of boundaries, exclusivity and control” (LEACH, 2007, p. 100) 
contextos, diversos autores apontam para a necessidade de questionarmos tal categoria. Na literatura sobre religiões de matriz africana, no Brasil, é bastante presente a sugestão de que se pense em uma pessoa compósita, combinada ou em modalidades de participação com entidades (GOLDMAN, 1984; 1987). José Carlos Gomes dos Anjos (2008), por exemplo, propõe que:

A possessão pode ser assim analisada como um ritual desterritorializante, em que um sujeito residual cede o corpo e a consciência a uma entidade que não mais coincide com o eu. 0 sagrado enquanto alteridade é carregado para "dentro" fazendo explodir a unidade do sujeito. (ANJOS, 2008, p. 85)

0 autor sugere ainda, a partir de pesquisa com um terreiro da cidade de Porto Alegre, que essa noção particular de pessoa não é inferior à definição de indivíduo, antes, a religiosidade afro-brasileira possui uma filosofia política - ou cosmopolítica que traz uma noção de pessoa que pode "contrapor a noção usual de sujeito político que emana da modernidade política ocidental" (ANJOS, 2008, p. 84). A filósofa Isabelle Stengers (2005) sugere o uso do termo "cosmopolítica" para a compreensão de relações que não passam apenas por humanos, mas que os conectam com outros seres - na medida em que as bordas entre os mesmos não são absolutas -, ou, nas palavras de Nyamnjoh (2015), passam por situações nas quais as pessoas podem ser percebidas como frontier beings.
Tomo como base a distinção entre concepções de pessoa como um dispositivo heurístico - como ficção que permitem mobilizar o pensamento -, uma vez que há momentos de controle dos corpos nas religiões afro-brasileiras encontradas no Maranhão, assim como há momentos de não controle absoluto do mesmo na economia, nas leis ou na medicina ocidentais (como sugere Palmié, 2006). Desloco, entretanto, o foco da possessão em si para demonstrar que, para além de acionar uma noção de pessoa que compartilha seu corpo com as entidades, a ideia de "governo" coloca em pauta a possibilidade de um compartilhar que é ainda mais amplo, na medida em que trata de ações que incidem sobre objetos, sobre a natureza e, desta forma, sobre o mundo (coabitado por seres diferentes). Sugiro que tal perspectiva - a coabitação - possa ser pensada a partir da ideia de convivialidade, proposta por Francis Nyamnjoh (2015):

Convivialidade é reconhecimento e provisão do fato ou realidade de ser incompleto. Se a incompletude é a ordem normal das coisas, natural ou de outra maneira, a convivência nos convida a celebrar e preservar a incompletude e mitigar as ilusões de grandeza que vêm com as ambições e clamores de completude. A convivialidade não apenas nos encoraja a reconhecer nossa própria incompletude, ela nos desafia a termos a mente aberta e sermos abertos às possibilidades de nossos clamores e articulações de identidades, ser e pertencimento. A convivialidade nos encoraja a alcançar, encontrar e explorar modos de

9. Nas palavras da autora: "Quero afirmar que cada conquista na ecologia da prática, isto é, cada (sempre parcial) relação entre práticas como tais, à medida que divergem, deve ser celebrada como um 'evento cósmico', uma mutação que não depende apenas de humanos, mas de humanos como pertencentes, o que significa que são obrigados e expostos por suas obrigações. Tal evento não é algo que possa ser produzido pela vontade" (STENGERS, 2005, p. 192, tradução nossa). 
engrandecer ou complementar a nós mesmos somadas às possibilidades de potência trazidas a nós pela incompletude de outros (humanos, naturais, super-humanos e supernaturais), nunca como uma manobra para tornar-se completo (em última instância, uma ilusão extravagante), mas para nos tornar mais eficazes em nossos relacionamentos e socialidade. (NYAMNJOH, 2015, p. 10) ${ }^{10}$

A perspectiva de um mundo não fechado - e logo, do reconhecimento dos limites do conhecimento sobre ele -, assim como a ideia de um mundo habitado por seres diversos, me parece importante para compreendermos os contextos etnográficos trabalhados neste texto. 0 material apresentado, nesse sentido, remete a duas localidades encontradas no interior do Maranhão. A primeira é a cidade de Codó, distante pouco mais de trezentos quilômetros da capital do estado, e conhecida em virtude de uma religião afro-brasileira chamada Terecô. 0 município, há alguns anos, alcançou certa notoriedade em função de trabalhos de pais e mães de santo supostamente realizados para políticos de destaque. A segunda narrativa remete a um povoado, no interior do município de Itapecuru-Mirim, chamado Santa Rosa dos Pretos, que tal como a cidade de Codó, cresceu às margens do Rio Itapecuru. No local existem terreiros de tambor de mina, com forte presença de encantados da mata e da linha de água doce. A partir do contar dos brincantes sobre a encantaria, procuro questionar algumas formas de falar sobre religião afro-brasileira no Maranhão na medida em que busco compreender a ideia de "governo", tal como apresentada pelas pessoas com as quais convivi.

\subsection{Terços quebrados e corpos imobilizados}

Em 2010, iniciei uma pesquisa de campo na cidade de Codó, considerada cidade berço do Terecô. Foi naquele ano que conheci Luiza (ou Dona Luizinha), mãe de santo de mais de 80 anos de idade, chefe de uma pequena tenda, contígua à cozinha de sua casa. Como convivemos muito nos últimos anos, conheci ainda seus familiares, alguns de seus encantados e suas filhas de santo - nove mulheres que ela tem aconselhado a procurar outras casas para continuarem com suas obrigações religiosas, pois, pretende de 'aposentar' e desfazer a tenda.

Entre as filhas de santo de Luiza está Rita, uma mulher de pouco mais de 50 anos, que é sua afilhada. Rita é filha de Benta, uma mulher que já faleceu, mas que foi muito importante na vida de Luiza, pois as duas perceberam a mediunidade na mesma época e juntas iniciaram sua "preparação” (ou iniciação) na religião, ainda muito jovens, no interior da região leste do Maranhão. A história que conto aqui, para

10. No original "Conviviality is recognition and provision for the fact or reality of being incomplete. If incompleteness is the normal order of things, natural or otherwise, conviviality invites us to celebrate and preserve incompleteness and mitigate the delusions of grandeur that come with ambitions and claims of completeness. Not only does conviviality encourage us to recognise our own incompleteness, it challenges us to be open-minded and open-ended in our claims and articulations of identities, being and belonging. Conviviality encourages us to reach out, encounter and explore ways of enhancing or complementing ourselves with the added possibilities of potency brought our way by the incompleteness of others (human, natural, superhuman and supernatural alike), never as a ploy to becoming complete (an extravagant illusion ultimately), but to make us more efficacious in our relationships and sociality”. (NYAMNJOH, 2015, p. 10) 
falar do governo dos corpos e dos objetos, é sobre Dona Benta e me foi contada em diferentes momentos, tanto por Luiza, quanto por Rita, no mês de agosto de 2017, quando estive em Codó na companhia de uma das minhas orientandas.

Luiza tinha mediunidade desde criança, e depois que foi preparada começou a atender pessoas em sua casa, com a ajuda dos encantados, e a fazer giras sem tambor. Dona Benta também possuía mediunidade e foi dançar na casa de Luiza. Paralelamente, segundo contou-nos Rita, ela recebeu duas pessoas em sua própria residência, para fazer remédios e purgantes, pois alguns de seus encantados trabalhavam com cura. Enquanto Luiza tornou-se mãe de santo, a história de Benta, entretanto, tomou outro caminho. Em virtude do seu envolvimento com o Terecô, ela passou a ser mal vista por alguns vizinhos que não viam a religião com bons olhos - nas palavras de Rita: "numa espécie de preconceito" ou "ignorância”. Não sabendo como proceder diante dessa situação, e muito afetada pela discriminação que viveu, Benta decidiu não trabalhar com os encantados e "os amarrou", ou seja, fez um trabalho espiritual para que não mais descessem.

Na conversa em sua casa, Rita me disse que "não se amarra encantado. Como ele pode vir aqui em outra pessoa se ele tá amarrado? Pode afastar ele, fazer um acordo, chamar ele, mas não amarrar. Só que mamãe disse que foi amarrar os encantados, mas aí os terços dela começaram quebrar”. Os terços são os guias, rosários ou cordões de conta utilizados no Terecô. 0 fato de se quebrarem indicava a agência dos encantados, e era um sinal de que as coisas não estavam bem. Tal como no contar de Rita, ouvi diversas histórias sobre a ação de encantados sobre objetos. Alguns deles eram deslocados pelas pessoas, mas continuamente voltavam aos "seus" lugares carregados pelas entidades; havia garrafas e copos que se quebravam de forma inesperada, sendo lidos como um sinal ou aviso de algum encantado sobre algo que deveria ser feito ou mesmo evitado; existiam objetos que deveriam ser guardados ou tocados apenas de determinadas maneiras, e outros que eram herança de mestres com os quais se aprendeu ofícios da encantaria; havia ainda objetos que pertenciam a determinada entidade: o vestido que a encantada Chica Baiana pediu; a toalha, o bolo ou as fitas de Rei de Minas, a taça de Dona Maria (Padilha) que não poderia ser utilizado por ninguém que não ela, incorporada por algum brincante.

Os encantados de Benta enviaram mensagens por intermédio dos terços e, a partir de então, segundo Rita, "a deixaram doente" - de forma que começou a emagrecer e não conseguiu mais caminhar, ficando onze meses sobre uma cama, sem poder se levantar. Depois de onze meses, ela faleceu, na época, com 30 anos de idade. No dia, todas as crianças da casa - eram cinco filhos - foram chamadas até seu quarto, para tomar benção. Nesse momento de despedida, ela "recebeu" seu encantado principal (seu guia ou chefe de croa), aquela que seria a entidade mais importante para ela. No momento em que chegou, ele colocou o corpo de Benta de pé, dizendo que ela não possuía nenhum problema de saúde, que antes não havia conseguido caminhar porque havia negado seus encantados. Na sequência, ele se despediu e ela faleceu.

Por mais que a história de Benta seja carregada de forte dramaticidade, ela não é, em nada, incomum na vida dos terecozeiros. Continuamente, são contadas experiências semelhantes, algumas remetem a situações 
de morte, como a de Dona Benta; outras são jocosas e divertidas, como quando se contava sobre alguma entidade que tirou a roupa de uma pessoa em quem incorporou, fez outra subir em árvore que não conseguiu descer, ou se apresentou em locais não muito usuais, fazendo a pessoa passar vergonha. Luiza e eu, naquele mesmo dia, tínhamos conversado sobre um encantado que derrubou uma senhora (em quem estava incorporado) de uma moto na saída da festa de uma tenda. A mãe de santo me explicou que isso acontece com alguns "Por que não bota corpo nas identidades dele, não acende vela" - ou seja, porque a pessoa não leva o encantado a sério e não "assume sua responsabilidade” com ele. Diante dessas condições, o encantado age sobre a pessoa para ela "criar vergonha, se não vai deixar ela com o cu pra cima todo tempo", isto é, dançando arcada, de um jeito pouco coordenado, considerado feio. É por isso que "tem que viver pra eles. [A pessoa] não se governa. Ela é governada. É ou não é do jeito deles”. A condição humana, ainda que necessária para a vinda do encantado (na medida em que se ocupa de um corpo), tem suas limitações diante do governo dos encantados, pois, como afirmou a Dona Luizinha, "a gente nunca vai saber a realidade toda da encantaria”.

\subsection{Os avisos dos donos dos rios e das matas}

No ano de 2017, por intermédio de um aluno cuja pesquisa acompanho, conheci uma comunidade quilombola chamada Santa Rosa dos Pretos, localizada no município de Itapecuru-Mirim, a 117 quilô- metros de São Luís. A situação que conto ocorreu quando fomos à comunidade em junho desse mesmo ano, para participar das atividades de um tambor de crioula realizado para atender a uma promessa para São Benedito. Ela foi vivida por mim e por uma colega de trabalho ${ }^{11}$, que há anos realiza pesquisa de campo no local, estudando, especialmente, as reivindicações em torno dos direitos da comunidade como quilombola, e as diversas obras e projetos de desenvolvimento que impactam no local: uma rodovia federal, linhões da rede de energia elétrica e a Estrada de Ferro Carajás, da mineradora Vale do Rio Doce (obras que levaram a uma diminuição do território, além de ocasionarem diversos problemas).

Em uma certa manhã, nos encontramos com alguns moradores, entre eles, Seu Libâneo, um senhor já idoso, liderança de Santa Rosa dos Pretos. Nós nos aproximamos do local onde Seu Libâneo estava conversando e nos sentamos. Durante a conversa, perguntamos sobre um sonho que ele teve, relacionado ao meio ambiente e aos encantados. Nossa pergunta, como exposto em outro texto (AHLERT e LIMA, no prelo), não foi respondida de forma imediata, mas introduzida com seu relato sobre a participação em um seminário no Instituto Federal de Ciência e Tecnologia do Maranhão (IFMA - Campus Itapecuru-Mirim), que discutia políticas de desenvolvimento. No seminário, depois de ouvir os palestrantes, Seu Libâneo tomou a palavra e se dirigiu aos presentes inquirindo: "Vocês falam em política compensatória, política satisfatória, mas vocês sabem o que é o meio ambiente? Ainda falam em política de desenvolvi-

11. Realizei essa conversa na companhia da professora e pesquisadora Cíndia Brustolin, a quem sou grata pela interlocução e generosidade. 
mento sustentável? Mas quem sustenta?". Nesse dia, ele havia questionado termos utilizados pelos pesquisadores - inclusive o de meio ambiente e a ideia de política compensatória -, e colocado seu ponto de vista sobre a questão, mostrando conhecer pessoalmente as mudanças ambientais.

Essa narrativa era um preâmbulo para nos contar sobre o sonho, o que aconteceu na sequência. Seu Libâneo então nos disse que "espíritos e invisiveis" (os encantados) apareceram em seu sonho, lhe indicando determinados lugares da comunidade, como os igarapés que tinham secado por causa da Estrada de Ferro Carajás. Nossa pesquisa no local tinha a ver exatamente com essa questão - como os impactos causados pelos grandes empreendimentos produziam transformações nas relações entre pessoas e encantados. Seu Libâneo sonhou com os igarapés que, como outras regiões de mata e poços de água no local, eram considerados moradas de encantados. Eles apareceram em seu sonho para avisar quanto ao perigo do assoreamento dos rios, do desmatamento das áreas de mata (os "satuba") e, consequentemente, da possibilidade de seu afastamento, pois há alguns encantados que estão ligados a esses espaços já que são percebidos como "donos" dos mesmos ou associados a lugares de encantaria.

Nas falas dos brincantes, em diferentes contextos de pesquisa, determinados espaços naturais parecem ter relação intensa com a encantaria ${ }^{12}$. É o caso de algumas pedras, árvores ou quedas d'água onde pessoas com mediunidade veem as entidades frequentemente. Em outros locais, essa presença se efetiva pois neles foram depositados (ou enterrados) os assentamentos um conjunto de elementos, especialmente pedras, considerados a própria entidade. A relação com a natureza também passa pela comunicação com as pessoas, pois, existem entidades que se materializam, por exemplo, em uma árvore, e a partir dela indicam tratamentos, curas e trabalhos. A despeito dessas diferentes formas de manifestação a partir da natureza e de determinados lugares, não é possível considerar elementos como pedras, cachoeiras, árvores, matas etc. como espaços inertes - à espera da ação e transformação humana - mas como parte constituinte de um mundo onde vivem e transitam diferentes seres.

Seu Libâneo nos ensinou, então, que o mundo era formado por três partes: "Pelo céu, onde está o paterno [Deus]. Pela terra e pelo mar. No mar mora vida. A vida é a encantoria. Quer você goste quer não, tem a encantoria”. Em outro momento, se referiu à encantaria falando sobre "povo do fundo", maneira de mencionar os encantados da linha de água doce - provavelmente aqueles que lhe trouxeram o alerta em seu sonho. Sobre esse mundo intensamente habitado, comentou ainda que "nesse mundo ninguém se governa” - dando a entender que os humanos participavam pouco da gestão dele, tal como ele percebia.

12. Penso não se tratar apenas de uma incidência dos encantados sobre a natureza, mas de processos mais complexos que relacionam a natureza, as entidades e as pessoas ao ponto de as enredarem (no sentido dado ao termo por Clara Flaksman, 2016). A ideia de entrosamento proposta por Julia Sauma (2014) é muito interessante e penso na possibilidade de diálogo com o cenário que descrevo, embora, aqui, me pareça menos central a ideia da diferença e da alteridade, apontadas, pela autora, como "fundamento" (p. 263) para a compreensão de uma "ecologia dos entrosamentos: uma forma de se relacionar com a paisagem e os seus diversos elementos-donos, a partir da diferença” (p. 267). 
Saber da importância dos encantados e conhecer a força da encantaria não era, entretanto, conhecimento compartilhado por todas as pessoas. Muitas sequer percebiam que a natureza é morada e governo dos encantados - que árvores, cachoeiras e águas têm donos, e que é necessário respeitar isso. Dona Dalva, uma praticante de religião afro-brasileira na comunidade disse que nem todas as pessoas estão aptas a reconhecer/perceber os sinais das conexões que acionam a natureza, a encantaria e as pessoas, ou seja, nem todo mundo consegue ter dimensão do impacto causado pelas agressões ao ambiente, pois "só entende quem se assume, quem frequenta [o terreiro]"13, ou seja, por aqueles que, nas palavras de Dalva respeitam - e nas de Luiza, se responsabilizam - (por) perceber o mundo como densamente habitado.

\section{Desconhecimento, pobreza e governo dos encantados}

Encantados, nas histórias que compartilhei nesse texto, agem sobre diversos elementos. No contar sobre Dona Benta - e em todas as histórias correlatas - fica evidente a ação dos encantados sobre objetos (os terços que se quebram) e corpos (a mobilidade e a imobilidade). Rabelo (2014) sugere, para pensar o candomblé nagô soteropolitano, que toda agência de uma entidade pressupõe um desagenciamento do sujeito na incorporação. Entretanto, vemos que o governo dos encantados ultrapassa a ocupação do corpo no momento da possessão, e o marca de forma mais ampla. Foi o que aconteceu com as mãos de Dona Concita, uma senhora idosa de uma comunidade quilombola de Codó, que ficaram manchadas porque recebia um encantado parteiro que não usava luvas para "pegar" crianças. Igualmente, aconteceu com Luiza, que compreendia que a debilidade de um dos seus braços era fruto da ação dos encantados. Em outro momento, mostrei como resíduos dos trabalhos com os encantados permaneciam nos corpos dos pais e mães de santo, e os consumiam, causando cansaço e envelhecimento (AHLERT, 2016).

Todavia, encantados não incidem apenas sobre objetos e corpos - que são impactados e transformados por suas presenças, mas também sobre a natureza e o mundo. Em torno disso discorriam Seu Libâneo e outros moradores de Santa Rosa dos Pretos, quando nos contavam sobre pedras, árvores e igarapés que eram moradas de encantados ou de entidades consideradas donas desses espaços. Certa vez, Seu Bigobar, pai de santo de Codó, comentou que, antigamente, quando os rituais religiosos eram realizados nas matas de babaçu, entravam nesses espaços apenas quem os encantados queriam, pois eles controlavam esse acesso, já que eram considerados encantados da mata.

A "força" dos encantados (sua potência de ação ou efeito sobre o mundo) era unanimemente percebida pelos brincantes. 0 governo dos encantados, nesse sentido, põe em pauta a incapacidade das pessoas, suas limitações. Isto se relaciona com a compreensão de que, nas religiões afro-brasileiras do Maranhão, o conhecimento e a eficácia (para curas e trabalhos, por exemplo) é dos encantados e não dos brincantes - sendo-lhes cedidas na medida em que 
interagem com as entidades. Por um lado, isso evidencia as limitações da ação humana, nem sempre dotada das potências e dos conhecimentos necessários para lidar com determinadas situações. Por outro, confırma algo presente nos dois casos narrados, que demonstram que participar dos terreiros é uma "brincadeira séria" (PACHECO, 2004) - que exige que se "assuma responsabilidade", que se "respeite".

Como sugeri no início do texto, minha intenção é lançar mão das falas sobre o governo dos encantados para pensar duas ideias recorrentes na pesquisa de campo no Maranhão, que interpelam as experiências com os encantados de forma negativa, as associando ao desconhecimento, à enganação e à pobreza. Buscarei, a partir desse tensionamento, falar sobre outros governos, sobre a produção de corpos, ontologias e espaços como inferiores ou mesmo inexistentes. Passo, portanto, a apresentar duas maneiras de contar sobre a relação entre pessoas e encantados, com o intuito de demonstrar que elas obliteram os sentidos concedidos pelos brincantes às interações com as entidades.

\subsection{Pobreza e religião}

A partir de 2010, quando comecei a fazer pesquisa no Maranhão, ouvi diversas vezes uma forma de explicar porque as pessoas eram brincantes. A explicação residia na pobreza: as pessoas eram pobres e era essa condição que as fazia participar das atividades de terreiros e tendas; ao mesmo tempo, frequentar esses espaços as condicionava a uma situação de pobreza (em uma espécie de processo de causa e efeito que se repetia infınitamente). Nessa perspectiva, evidentemente, a pobreza não se reduzia a uma questão socioeconômica, mas remetia ao desconhecimento, à falta de escolaridade, à certa ausência de esclarecimento e muito provavelmente, à raça. Tal explicação era presente nas falas das pessoas com as quais eu interagia na cidade de Codó e que não participavam diretamente das atividades das tendas onde eu fazia pesquisa de campo - mas que eu encontrava nos serviços por mim utilizados (pousadas, lojas e restaurantes) e nas conversas cotidianas que eu mantinha com pessoas diversas, como alguns funcionários públicos (professores, bibliotecários e técnicos administrativos) curiosos com minha presença no local.

É importante pontuar, para iniciar um contraponto à tal perspectiva, que receber encantado não é, para os brincantes, uma escolha. A mediunidade, dizem, é de nascença. Essa é uma das acepções de governo, na medida em que lidar com uma entidade não passa por algum desejo da pessoa, escolha ou livre arbitrio. Esse governo, que indica certo domínio, aparece em outras frases, como a dita pelo encantado de uma mãe de santo de Codó que, na primeira vez que "veio", afırmou: “a menina agora é minha”, como se dissesse que agora ela precisava lidar com sua presença em sua vida. Sugerir uma relação direta entre pobreza e pertencimento religioso, ignora, portanto, a maneira como os brincantes percebem o "ter mediunidade”, “o receber encantado”, pois, do seu ponto de vista, não se trata de uma escolha ou de uma condição que se coloca a partir de uma situação de carência material.

Igualmente, "carregar encantado" não é percebido como fruto de desconhecimento - como parece sugerir tal afirmação ao pensar a pobreza como falta de escolaridade ou de esclarecimento -, mas antes como processo de aprendizado e ampliação de um repertório de ações. Ou seja, quando 
uma pessoa possui mediunidade, ela precisa, em determinado momento, lidar com as manifestações das entidades e para isso são acionados diversos sujeitos: familiares, curadores, rezadores, pais e mães de santo, além de encantados que ensinam como proceder. Nesses contatos, se amplia o conhecimento sobre remédios, purgantes e banhos curativos, sobre rezas e pontos cantados, sobre formas de cuidado e de compreensão do que se passa no universo. Este conhecimento em expansão não é puramente escolar ou dado de forma direta.

Existem maneiras variadas de lidar com a encantaria, algumas consideradas bem sucedidas e outras não. É dessa forma que Rita observa que o problema de sua mãe não foi, em si, não querer trabalhar com os encantados - seu problema foi utilizar-se de uma medida errada para isso, “amarrar” as entidades. Dona Luizinha, na mesma conversa sobre Benta, me disse que nem sempre conseguia cumprir com todos os pedidos que lhe eram endereçados pelos seus encantados, mas que diante disso sua postura era "não dá de um jeito, tenta de outro jeito. Diz que não tem, que não pode aquilo, mas que pode fazer outra coisa”. A mãe de santo apontava assim para uma dimensão de abertura, incerteza, aposta e de construção conjunta da relação entre humanos e não humanos.

A construção conjunta dessa relação ainda nos ajuda a destacar outro aspecto bastante importante de como funciona esse governo - em alguma medida o encantado não é um outro -, completamente aparta- do e claramente definido em relação ao seu "cavalo". 0 "carregar encantado" fala de uma composição (GOLDMAN, informação oral) ou de modalidades de participação (AHLERT, 2016), de maneira que ambos se constroem mutuamente e se impactam de formas diversas.

Se conceber outra noção de pessoa e de corporalidade permite questionar certa ideia de sujeito individual ocidental, possibilita ainda desconfiar de outra tendência de parte da literatura que me parece relacionada à associação entre pobreza e religião, qual seja, aquela que pensa a relação entre pessoas e entidades como clientelismo e patronagem ${ }^{14}$. Patronagem e clientelismo foram termos utilizados por determinada antropologia da política para se referir a situações de desigualdade onde um patrão, detentor de maior poder (financeiro, político, social), se colocaria na posição de doador de um favor a uma pessoa de condição inferior, que lhe retornaria com declarações de lealdade e compromisso ${ }^{15}$. Essa situação assimétrica de troca ocorreria com maior recorrência em grupos onde o Estado seria menos desenvolvido ou ainda em formação.

Tanto na associação entre pobreza e religião, quanto na imposição da ideia de patronagem para pensar a relação entre pessoas e encantados, a mediunidade é vista como algo primitivo (enquanto anterior) e mesmo provisório - algo que ocupa espaço em contextos de racionalidade e Estado precários ou de instabilidade financeira. Nessas formas de perceber a relação en-

14. Ver MITSCHEIN, T.; MIRANDA, H.; PARAENSE, M. Urbanização selvagem e proletarização passiva na Amazônia: o caso de Belém. Belém: Cejup, 1989; SILVA, A. V. 0 Tambor das Flores: uma análise da Federação Espírita Umbandista e dos Cultos Afro-Brasileiros do Pará (1965-1975). Belém: Paka-Tatu, 2015. 15. Ver, por exemplo, Foster (1967); Pitt-Rivers (1971); Wolf (1966); Silverman (1967) e Gellner (1977). 
tre pessoas e encantados, são ignoradas as perspectivas dos brincantes - que ganham forma conceituando a mediunidade como um fenômeno que acompanha as pessoas desde o nascimento e que veem o engajamento com as entidades como expansão de conhecimentos -, assim como são negadas particularidades e agência a seres diversos que, ainda que não sejam uma alteridade absoluta na medida em que estão compondo humanos, terminam por ser percebidos por chaves utilizadas para falar - e falar de forma depreciativa, na maior parte dos casos -, de relações entre pessoas.

\subsection{Ações dos encantados e seus limites}

A segunda abordagem recorrente sobre a encantaria e a pobreza, que ouvi diversas vezes durante o campo e que gostaria de pensar a partir das considerações sobre o governo, enfatiza o quanto a religião era uma espécie de ocultamento ou falseamento da realidade, pois impediria que as pessoas enxergassem ou permitia que se iludissem com aspectos relacionados à política. Explico melhor. Como afirmei de forma breve, anteriormente, é comum ouvir referências a alguns pais e mães de santo do Maranhão como guias espirituais de políticos em altos cargos no Executivo brasileiro. Diante disso, algumas pessoas inquiriam: se tal apoio fosse possível, ou seja, se pais e mães de santo (ou os encantados) tivessem poderes de influenciar eleições, por exemplo, por que o Maranhão seria um dos estados mais pobres do Brasil? Ou seja, por que as entidades não agiriam sobre as situações de vulnerabilidade encontradas nesse contexto? Essas perguntas surgiam, especialmente, nos meios de comunicação, quando algum pai ou mãe de santo concedia entrevista sobre seus trabalhos, quando era publicada alguma reportagem em periódico local ou nacional sobre a trajetória de algum mestre ou, ainda, quando alguma festa de terreiro era divulgada na televisão ou rádio.

Inicio a problematização a esta questão a partir de duas colocações sobre as quais, me parece, ela se assenta. A primeira é a de que encantados e pessoas possuem as mesmas preocupações, ou seja, ela sugere uma equivalência ou espelhamento entre ambos os seres: humanos perguntam, entidades respondem. Ela pressupõe, tal como o faz a aplicação da categoria patronagem, que as preocupações que deveriam importar aos encantados são as mesmas colocadas às pessoas. Ao mesmo tempo em que se infla a agência humana (ela é que pauta questões), se nega a possibilidade dos encantados - cujo conhecimento ancestral e poderes estão para além dos humanos -, terem suas próprias lógicas de funcionamento e operação.

Os brincantes, ainda que não tratem os encantados com diversas regras posturais, preceitos e distinções, pois conversam, discutem, bebem, riem e se divertem com os mesmos, - tem muito clara a dimensão da seriedade desse engajamento. A "brincadeira séria" e a necessidade de "assumir a responsabilidade" ganham materialidade nos diversos relatos, tanto de punições como de apoios e auxílios concedidos pelos encantados quando se trabalha ou se cuida deles. Nada supõe que a postura humana rege a relação, antes, como sugere a frase de Luiza, a pessoa "é governada" - sua autonomia é limitada dentro na interação (e quiçá, no mundo como um todo, onde diversas forças não passam pelo controle humano).

A segunda consideração sobre a qual se estabelece a questão aqui tratada, remete à natureza da "força" ou das capacidades de 
ação dos encantados. Para falar sobre ela, retomo a fala de Seu Libâneo, quando relatava, com certa apreensão, as alterações ambientais e os efeitos que elas causavam nas relações com as entidades. Nesse sentido, avalio, ele não falava apenas do governo das entidades sobre a natureza, mas das ameaças a esse governo, na medida em que ele não é transcendente ao/independente do que se passa no mundo. Neste caso, ainda que os encantados sejam donos de determinados espaços da natureza, eles estão sendo afastados ou deslocados de seus domínios pelas obras de desenvolvimento presentes nos grandes empreendimentos. Compreendo, portanto, que, ao mesmo tempo que destacam as capacidades de governar, as histórias contadas falam de limites das ações das entidades (ou em um poder que não é absoluto).

Ao sugerir que a existência e a força dos encantados funcionem (ou devessem funcionar) como mero reflexo de questões humanas, se perguntar por que os encantados não transformam as situações de precariedade econômica oblitera uma questão fundamental nas situações etnográficas trazidas neste texto, que pautam, antes, sobre como se relacionar com os encantados -, seja na própria trajetória (como no caso de Benta), seja em mundo habitado por forças diversas, capazes de deslocar entidades (como narrou Seu Libâneo). Nos casos contados, a preocupação me parece ser com a coexistência, com a coabitação entre seres de estatutos diferentes, portadores de lógicas diferenciadas. 0 que se coloca é: como manter respeito ${ }^{16}$ e responsabilidades diante das dedicações, violências e transformações que atuam sobre a vida das pessoas.
Entre esses processos de violência e transformação podemos pensar no sofrimento produzido pelo preconceito em relação à religião, que incidiu sobre Dona Benta e que mobilizou suas ações, de forma que, mesmo sabendo que não deveria, ela tentou “amarrar" seus encantados - afastá-los do seu corpo, de sua casa e da sua convivência. Diante desse procedimento, os encantados se apresentaram, para ela, de outra forma: modularam sob outra perspectiva sua relação com a brincante. Igualmente, as mudanças no meio ambiente, postas pelos grandes projetos que impactam na comunidade de Seu Libâneo - e toda a violência que elas carregam -, afastam encantados que moram e governam certos espaços naturais.

\section{Considerações finais}

Neste texto, discorri sobre ideia de "governo" partindo de duas histórias contadas por pessoas que convivem com encantados - entidades recebidas nas religiões afro-brasileiras presentes no estado do Maranhão. Em primeiro lugar, descrevi a história de Benta, tal como me foi narrada por Rita e Luiza, para tratar da ação dos encantados sobre objetos e corpos, na medida em podem transformá-los, prejudicá-los ou mesmo potencializá-los. Na sequência, contei a forma como Seu Libâneo percebe, com ajuda e o alerta dos encantados, a incidência de grandes empreendimentos realizados em nome do desenvolvimento, que colocam em questão o domínio destes seres sobre a natureza e apresentam o risco de seu afastamento.

Minha intenção com essas histórias que pautam importantes debates sobre pessoa, propriedade, domínio -, foi provocar os textos de Josiane do Espirito Santo Pires da Silva (2017) e Joércio Pires da Silva (2017). 
algumas leituras endereçadas a explicar porque as pessoas se relacionam com encantados, porque frequentam tendas e terreiros no Maranhão. As leituras por mim ouvidas em campo, ou mesmo divulgadas na mídia local, acionam chaves como pobreza, desconhecimento e ignorância como fatores explicativos para a incorporação, a ida aos terreiros, a realização dos rituais e, dessa forma, negam as versões dos brincantes sobre a maneira como percebem e vivem sua relação com as entidades. Nelas, só é possível ser brincante na medida de uma ausência - de dinheiro, de conhecimento, de esclarecimento.

Igualmente, para essas explicações, encantados não existem e, por isso, concebê -los como parte da vida só pode ser engano, desconhecimento ou ignorância. Eles são reduzidos, portanto, a mero reflexo de pautas impostas pelas relações entre humanos, capturados por preocupações exógenas, enquadrados em conceitos nos quais não se encaixam quando se interpreta para que deveriam servir ou trabalhar. Na mesma medida em que encantados são decretados como inexistentes - por aqueles que têm preconceito ou pela ação de uma grande empresa que não se interessa por esse tipo de ocupação do mundo -, também as pessoas com as quais eles convivem passam a habitar um contexto de negação e invisibilidade, pois lhes resta apenas o lugar do engano e da não compreensão do mundo.

A versão dos brincantes não é considerada apta a dialogar com as explicações sobre seu engajamento com as religiões afro -brasileiras. Eles, por sua vez, não agem de forma aleatória ou impensada. Antes, buscam formas de lidar com a mediunidade que vão sendo construídas e experimentadas durante suas vidas, na perspectiva de que não existe regra pronta ou conheci- mento escolar para dirigir a interação com as entidades. Nesse percurso, a agência humana não é absoluta - ou como dizia Seu Libâneo "nesse mundo ninguém se governa” -, e o saber sobre o mundo não é totalizante, ou como afirmava Dona Luizinha: "a gente nunca vai saber a realidade toda da encantaria”. 0 mundo, atravessado por forças, potências e violências, é densamente habitado.

\section{Referências}

AHLERT, M. Cidade relicário: uma etnografia sobre terecô, "precisão" e encantaria em Codó (MA). 2013. 282 f. Tese (Doutorado em Antropologia Social) - Instituto de Ciências Sociais. Universidade de Brasília/UnB, Brasília, 2013.

Carregado em saia de encantado: pessoa e transformação no Terecô de Codó (Maranhão Brasil). Etnográfica, v. 20, n.2, p. 275- 294, 2016.

AHLERT, M. LIMA, J. Y. S. “Nesse mundo ninguém se governa”: encantaria e luta em Santa Rosa dos Pretos (Itapecuru-Mirim/ Maranhão). No prelo.

ANJOS, J. C. G. No território da linha cruzada: a cosmopolítica afro-brasileira. Porto Alegre: Ed. UFRGS/Fundação Cultural Palmares, 2006.

A filosofia política da religiosidade afro -brasileira como patrimônio cultural africano. Debates do NER, ano 9, n. 13, p. 77-96, jan./jun. 2008.

BARROS, S. C. Encantaria de Bárbara Soeira: a construção do imaginário do medo em Codó - MA. 2000. Dissertação (Mestrado em Sociologia). Universidade de Brasília, Brasília. 2000.

BORGES, A. M. Etnografia do Ordinário: reflexões sobre a necessidade de deslocamentos antropológicos na compreensão das formas estatais. In: VII REUNIÃO DE ANTROPOLOGIA DO MERCOSUL. Anais da VII Reunião de Antropologia do Mercosul. Porto Alegre, 2007. 
Bruxaria e Estado como (pré) conceito: contrastes etnográficos e limites da linguagem em antropologia. In: $32^{\circ}$ ENCONTRO ANUAL DA ANPOCS, Anais do $32^{\circ}$ Encontro Anual da ANPOCS. Caxambu, 2008.

CRUZ, A. T. D. Manipulando socialidades: 'pessoas', 'mistérios' e prestações rituais. Apresentação oral na 29a REUNIÃO BRASILEIRA DE ANTROPOLOGIA. Anais da 29a Reunião Brasileira de Antropologia. Natal, 2014.

CUNHA, 0. M. G. Metamorfose infinita: sobre brujos, espíritos e apuntes em Havana. História, Ciências, Saúde - Manguinhos, v. 22, p. 483-505, 2015.

FERRETTI, M. Desceu na guma: o caboclo do Tambor de Mina em um terreiro de São Luís - a Casa Fanti-Ashanti. São Luís: Edufma, 2000.

Maranhão encantado: encantaria maranhense e outras histórias. São Luís: Ed. UEMA, 2000b.

FLAKSMAN, Clara. Relações e narrativas: o enredo no candomblé da Bahia. Religião e Sociedade, n. 36, v. 1, p. 13-33, 2016.

FOSTER, G. M. The dyadic contract: a model for the social structure of a Mexican peasant village. In: POTTER, J. M. Peasant society: a reader. Boston, Little Brown, 1967, p. 213-230.

GELLNER, E. Patrons and clients. In: GELLNER, E. Patrons and clients in Mediterranean societies. London, Duckworth, Center for Mediterranean Studies of the American Universities Fiels Staff, 1977. p. 1-6.

GIUMBELLI, E. A presença do religioso no espaço público: modalidades no Brasil. Religião e Sociedade, v. 28, n. 2, p. 80-101, 2008.

GOLDMAN, M. A possessão e a construção ritual da pessoa no Candomblé. 1984. Dissertação (Mestrado em Antropologia Social) Museu Nacional, Universidade Federal do Rio de Janeiro/UFRJ, Rio de Janeiro, 1984.

. A construção ritual da pessoa: a possessão no Candomblé. In: MOURA, C. E. M. Candomblé: desvendando identidades. São Paulo: EMW Editores, 1987. p. 87-119.

JOHNSON, P. Uma genealogia atlântica da "possessão de espíritos”. Translating the Americas, v. 2, p. 65-100, 2014.

LEACH, J. Creativity, Subjectivity and the dynamic of possessive individualism. In: HALLAM, Elizabeth. INGOLD, Tim (Eds.) Creativity and Cultural Improvisation. Berg, 2007, p. 99-116.

LÉVY-BRUHL, L. A mentalidade primitiva. São Paulo: Paulus, 2008.

MBEMBE, A. 0 tempo que se move. Cadernos de campo, n. 24, p. 369-397, 2015.

NDEBELE, N. The rediscovery of the ordinary: some new writings in South Africa. Journal of Southern African Studies, v. 12, n. 2, p. 143-157, 1986.

NYAMNJOH, F. Incompleteness: frontier Africa and the currency of conviviality. Journal of Asian and African Studies, Leiden, v. 50, n. 2, p. 1-18, 2015.

PACHECO, G. B. F. Brinquedo de cura: um estudo sobre a pajelança maranhense. 2004. Tese (Doutorado) - Museu Nacional, Universidade Federal do Rio de Janeiro/UFRJ, Rio de Janeiro, 2004.

PALMIÉ, Stephan. Thinking with Ngangas: Reflections on Embodiment and the Limits of 'Objectively Necessary Appearances'. Comparative Studies in Society and History, n. 48, p. 852-886, 2006.

PITT-RIVERS, J. A. Friendship and authority. The people of the Sierra. Chicago, The University of Chicago Press, p. 137-159, 1971.

RABELO, M. Enredos, feituras e modos de cuidado: dimensões da vida e da convivência no candomblé. Salvador: Edufba, 2014.

SAUMA, Julia. Entrosar-se, uma reflexão etnográfica afroindígena. Cadernos de Campo, n. 23, p. 257-270, 2014.

SILVA, J. P. Tambor não é só tradição, é também força e resistência: o Tambor de Crioula no terri- 
tório quilombola Santa Rosa dos Pretos. Monografia (Graduação). Pedagogia da Terra. Universidade Federal do Maranhão, 2017.

SILVA, J. E. S. P. A minha mãe tirou meu diploma de caixeira sem eu saber: o festejo do Divino Espírito Santo como fortalecimento da cultura no território quilombola de Santa Rosa dos Pretos. 2017. Monografia (Graduação) - Pedagogia da Terra, Universidade Federal do Maranhão/UFMA, 2017.

SILVERMAN, S. The community-nation mediator in traditional central Italy. In: POTTER, J. M. et al. Peasant Society: a Reader. Boston: Little Brown, 1967. p. 279-293.

STENGERS, I. Introductory notes on an ecology of practices. Cultural studies review, v. 11, n. 01, 2005, p. 183-196.

WOLF, E. R. Kinship, friendship and patron-client relations in complex societies. In: BANTON, M. (Ed.). The social anthropology of complex societies. London: Tavistock, 1966, p. 1-22. 
RESUMO

0 artigo trabalha com a ideia de "governo" tal como empregada por pessoas que convivem com encantados - seres presentes nas religiões afro-brasileiras no Maranhão. Ao falar sobre o governo de corpos, de objetos e da natureza, busca problematizar determinadas associações entre pobreza, desconhecimento e religião. Sugere que essas associações não apenas negam a agência dos encantados quanto classificam sujeitos e suas práticas como falsas e incongruentes.

\section{PALAVRAS-CHAVE}

Encantaria, etnografia, corpos, natureza, governo.

\section{ABSTRACT}

This paper deals with the idea of "governance" such as used by people who live together with the enchanted - beings present in the Afro-Brazilian religions in Maranhao. By talking about the "governance" of bodies, objects and nature, it looks towards problematizing certain associations with poorness, ignorance and religion. It suggests that these associations not only deny the acting of the enchanted but also rank subjects and their practices as false and incongruous.

\section{KEYWORDS}

Enchantment, ethnography, bodies, nature, governance.

Recebido em: 15.01.18

Aprovado em: 13.06.18 